\title{
'Phormidin', a novel, better fatty acid synthase inhibitor from marine cyanobacteria, Phormidium Ambiguum
}

\author{
Prasanth $\mathrm{S}^{1}$, ARUN $\mathrm{G}^{2}$, Haridas $\mathrm{M}^{2}$, and Sabu ABDULHAMEED ${ }^{1}$ \\ ${ }^{1}$ Kannur University \\ ${ }^{2}$ Kannur University - Thalassery Campus
}

April 28, 2020

\begin{abstract}
Background and Purpose: Fatty acid synthase (FAS) is an attractive drug target for the treatment of cancer, obesity and microbial infections. Since FAS has an important role in primary metabolic process, targeting FAS by non-cross-reacting inhibitors will be operationally difficult to implement, though attractive. Experimental Approach: A novel FAS inhibitor, Phormidin, from the marine cyanobacteria, Phormidium ambiguum is reported. Its structure is similar to C75, the FAS inhibitor with a 17 carbon aliphatic chain and an open 6 carbon ring. But, it is comparatively less similar to Celurinin, another known FAS inhibitor lacking the epozxy ring. Key Results: In vitro assay of phormidin cytotoxicity with A549 lung carcinoma cell line showed it to be more active than cerulenin and C75, with an IC50 value $76.034 \mu \mathrm{g} / \mathrm{mL}$, compared to $86.419 \mu \mathrm{g} / \mathrm{mL}$ for Cerulenin and $99.034 \mu \mathrm{g} / \mathrm{mL}$ for C75. Conclusion and Implications: Enzyme inhibition assay of microbial and mammalian FASs showed promising results, with potential to develop better FAS inhibitor drugs.
\end{abstract}

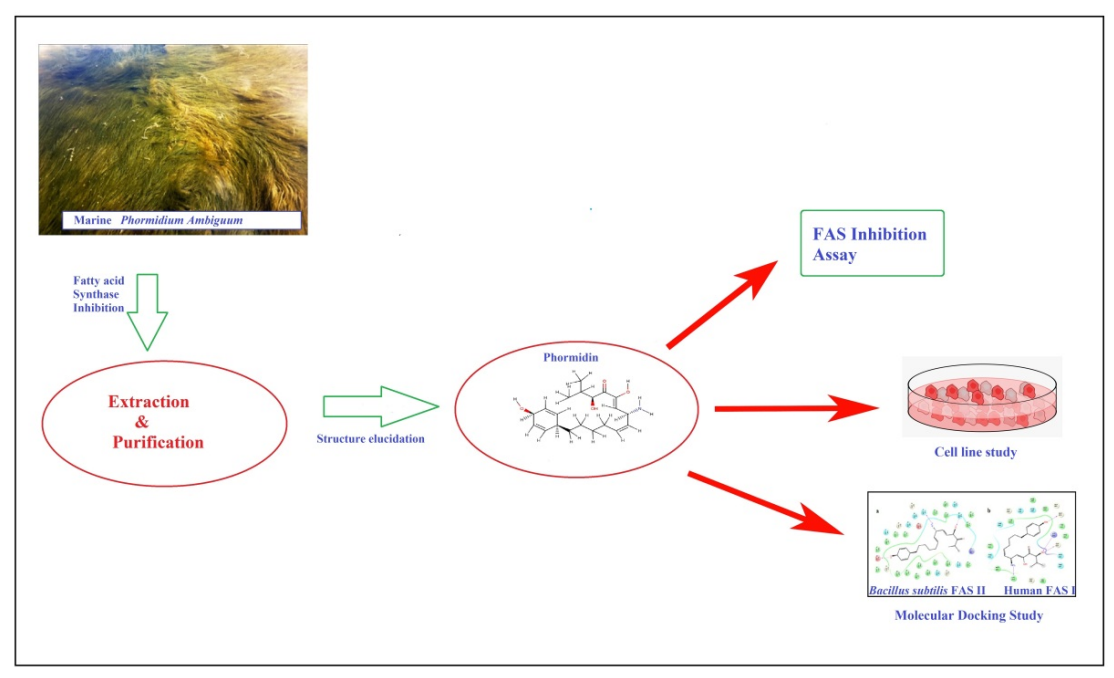

\section{Introduction}

Fatty acids play very important and diverse roles in living organisms, such as signal transduction, energy management and maintaining structural integrity to the normal metabolic process. Fatty acid synthases (FAS) are widely found in prokaryotes and eukaryotes, although their structures and functions vary. Fatty 
acids play a very important role in keeping the metabolic functions normal and are primary metabolites synthesized by a system of complex and tightly controlled biosynthetic machinery (Liu et al ., 2010). Bacteria and plants have type II FAS by which fatty acid synthesis is performed by a set of individual enzymes (White et al ., 2005). Type I FAS, found in animals and fungi, consist of huge molecular assemblies with separate catalytic domains to stitch on the designated fatty acid synthesis, with each catalytic domain acting as unique enzyme (Maier et al ., 2010; Wakil, 1989). In both type I and type II FAS, there is a common acyl carrier protein (ACP) acting as the mobile domain, shuttling the intermediate fatty acid substrates to various catalytic sites.

Studies have identified that FAS can be a promising drug target for cancer (Chalbos et al., 1987; Kuhajda et al ., 1994; Migitaet al ., 2009; Vazquez-Martin et al ., 2008; Wang et al ., 2004). Inhibition of FAS might lead to apoptosis of cancer cells (Zhou et al ., 2003; Deepa et al ., 2013). Since FAS is associated with mycolic acid biosynthesis it could be a TB drug target (Bhatt et al., 2007), with low possibility of drug resistance and toxicity due to the difference in the FAS systems of human and bacteria (Gago et al ., 2011).

There are many molecules that target FAS, like Epigallocatechin, Cerulenin, Orlistat, Pyrimidine, Triclosan, C75, CM55 etc., differing in modes of action and eliciting severe side effects (Brusselmans et al ., 2003; Moche et al ., 1999; Kridel et al ., 2004; Loftus et al ., 2000; Liu et al ., 2002; Rendina et al ., 2005; Tadao et al ., 1974). Hence, new FAS inhibitors are in demand.

Marine microbial sources have become one of the major focuses of research for identifying new chemical entities with diverse biological activities. Cyanobacteria are known to produce molecules with diverse pharmacological properties (Wijffels et al ., 2013; Dixit et al ., 2013). In this study, a FAS inhibitor was successfully isolated from the marine cyanobacteria, Phormidium ambiguum which could form a lead molecule for drugs against many diseases ranging from cancer to TB.

\section{Materials and methods}

\subsection{Collection and preparation of sample}

Phormidium ambiguum Gomont was collected from the Edakkad beach, Kannur Dist, Kerala, (GPS coordinates $11^{\circ} 49^{\prime} 09.9^{\prime \prime} \mathrm{N} 75^{\circ} 25^{\prime} 02.9^{\prime \prime} \mathrm{E}$ ) from a depth of 0.5 to $1 \mathrm{~m}$. The washed cyanobacterial biomass was grinded to fine paste, dried under vacuum and stored at $-20{ }^{\circ} \mathrm{C}$.

\subsection{Isolation of compound}

Approximately $500 \mathrm{~g}$ of the powdered cyanobacterial mass was defatted with hexane and Soxhlet-extracted at $65{ }^{\circ} \mathrm{C}$ with chloroform for about 6 to $8 \mathrm{hrs}$. The chloroform extract was concentrated to $1 / 5$ th the volume using a rotary vacuum evaporator (IKA, Germany) at $150 \mathrm{rpm} / 40^{\circ} \mathrm{C}$. Fatty acid synthase (FAS) inhibition assay gave positive result with the extract and it was marked as the property at every step involved in the purification of the compound/s. The concentrate was then added to excess of methanol in a separating funnel, stirred and kept overnight till a greenish precipitate was formed. The greenish precipitate was removed and re-dissolved in minimal amount of chloroform. This step was repeated until the precipitate turned pale white. The pale white waxy precipitate was further purified by $240 \mathrm{H}$ silica gel column chromatography ( 5 x 30 cm column). The column was subjected to gradient elution by ethyl acetate to methanol and finally by dichloromethane. Further purification was carried out by vacuum liquid chromatography with TLC grade silica $60 \mathrm{H}$ in $1.5 \times 15 \mathrm{~cm}$ column. Elution was carried out from $100 \%$ dichloromethane to $100 \%$ methanol. All the chemicals used were from Merck, India. Final purification of the compound was done by reverse phase chromatography, using Agilent 1200 High Pressure Liquid Chromatographic (HPLC) system equipped with Extend-C18 column of $1.8 \mu \mathrm{m}, 2.1$ x $50 \mathrm{~mm}$, Diode Array Detector in combination with Chem32, and Chemstation softwares. Gradient elution was performed with acetonitrile to water at a constant flow rate of $0.2 \mathrm{~mL} / \mathrm{min}$ with a constant column temperature of $30^{\circ} \mathrm{C}$.

\subsection{Structure elucidation}

Infrared (IR) spectra were recorded on a Shimadzu 8900 FTIR spectrophotometer as neat. Molecular weight 
of the compound was determined by LCMS/MS using Waters Xevoß G2-QT equipped with Aquity BEH C18 $1.7 \mu \mathrm{m}$ column, having $2.1 \times 50 \mathrm{~mm}$ dimensions. ${ }^{1} \mathrm{H}$ NMR spectra were recorded on a Bruker NMR spectrometer and the chemical shifts were expressed in $\delta(\mathrm{ppm})$ with trimethylsilane as the internal reference. ${ }^{1} \mathrm{H}-\mathrm{NMR}$ and ${ }^{13} \mathrm{C}-\mathrm{NMR}$ spectra were recorded on a Brucker AV500 Spectrometer, operating at $500 \mathrm{MHz}$ for ${ }^{1} \mathrm{H} \mathrm{NMR}$ and $500 \mathrm{MHz}$ for ${ }^{13} \mathrm{C}$ spectra. The chemical shifts were given in ppm $(\delta)$ and were referenced relative to $\mathrm{CDCl}_{3}$ ( $\delta 7.26$ and $77.24 \mathrm{ppm}$ for ${ }^{1} \mathrm{H}$ and ${ }^{13} \mathrm{C}$ NMR respectively). Activity spectra of the identified compound were predicted using PASS prediction server (http://www.way2drug.com/PASSOnline/) (Filimonovet al., 2004) which generated FAS as possible lead target enzyme.

\subsection{Determination of In vitro cytotoxic effect on cultured Cells}

L929/A549 cell lines were purchased from National Centre for Cell Science (NCCS), Pune, India. Cultures were maintained in Dulbecco's modified eagles media (Himedia, India) supplemented with $10 \%$ fetal bovine serum (FBS) (Invitrogen) and grown to confluence at $37{ }^{\circ} \mathrm{C}$ and $5 \% \mathrm{CO}_{2}$ in a humidified atmosphere using a $\mathrm{CO}_{2}$ incubator (NBS, Eppendorf, Germany). The cells were trypsinised ( $500 \mu \mathrm{L}$ of $0.025 \%$ Trypsin in PBS/0.5 mM EDTA solution (Himedia, India) for $2 \mathrm{mts}$ and passed to T flasks under aseptic condition. Test compounds were added to grown cells at a final concentration of $6.25,12.5,25,50$ and $100 \mu \mathrm{g} / \mathrm{mL}$ from a stock of $1 \mathrm{mg} / \mathrm{mL}$ and incubated for $24 \mathrm{hrs}$. The percentage difference in viability was determined by standard MTT assay (Arung et al ., 2000) after 24 hrs of incubation.

\subsection{Preparation of bacterial FAS for FAS inhibition assay}

Crude FAS containing protein fraction was isolated according to the modified protocol of Ahmad et al. (1981). Stock culture ofBacillus subtilis was inoculated in $100 \mathrm{~mL} \mathrm{LB}$ broth $\mathrm{pH} 7.2$ and cultured for $24 \mathrm{hrs}$ at room temperature. It was used for further inoculation of four $1000 \mathrm{~mL}$ flasks with same media and culture conditions. The flasks were placed in a rotator shaker to ensure adequate suspension of cells. Bacteria were harvested during the late-exponential phase of growth by centrifugation at $10000 \mathrm{x}$ g for $10 \mathrm{~min}$ and washed twice with $50 \mathrm{mM}$ sodium phosphate buffer $(\mathrm{pH} 7.0)$. Cell pastes were stored at $-20{ }^{\circ} \mathrm{C}$ until use.

\subsubsection{Preparation of cell free extracts.}

Frozen cell paste $(25-35 \mathrm{~g})$ was thawed and suspended in $50 \mathrm{mM}$ sodium phosphate buffer ( $\mathrm{pH} 7.0)$. The cell suspension was disrupted by sonication $(12 \mathrm{~W}, 6 \times 15$ pulses with 15 sec intervals) in $2 \mathrm{~mL}$ Eppendorf tubes containing $1.5 \mathrm{~mL}$ of cell suspension, supplemented with lysozyme $(250 \mu \mathrm{g} / \mathrm{mL}$, $)$ in a sonicator at 4 ${ }^{\circ} \mathrm{C}$. Unbroken cells and cell debris were removed by centrifugation at $30000 \mathrm{x} \mathrm{g}$ for $30 \mathrm{~min}$ at $4{ }^{\circ} \mathrm{C}$. The pellets were re-suspended in $50 \mathrm{mM}$ sodium phosphate buffer ( $\mathrm{pH} 7.0$ ) and made up to appropriate volume and subjected to ammonium sulphate precipitation. Solid ammonium sulphate was added and the proteins precipitated at 40-60\% saturation was collected by centrifugation, dialyzed and used for assay.

\subsection{Extraction of crude protein from bovine liver}

Crude preparation of FAS enzyme was made according to modified protocol of Dulter et al . (1971). Liver from freshly slaughtered Indian water buffalo was collected and transported in ice bucket and kept at $4{ }^{\circ} \mathrm{C}$. The liver was processed at the earliest by removing connective tissues and sliced into small pieces. About 750 $\mathrm{g}$ of liver was minced in a blender into suspension with $0.05 \mathrm{M}$ Potassium phosphate buffer $\mathrm{pH} 7.4$ containing $1 \mathrm{mM}$ EDTA, to make up to a volume of $2.5 \mathrm{~L}$. The thick solution was centrifuged at $7500 \mathrm{x} \mathrm{g}$ for $20 \mathrm{~min}$ to remove meat debris and supernatant was further centrifuged at $30000 \mathrm{x}$ g for $30 \mathrm{~min}$ to get a translucent solution. The supernatant was further diluted to specific volume with $0.05 \mathrm{M}$ Potassium phosphate buffer $\mathrm{pH} 7.4$ with $1 \mathrm{mM}$ EDTA and brought initially to $10 \%$ and then to $40 \%$ saturation with solid ammonium sulfate at $4{ }^{\circ} \mathrm{C}$. The $40 \%$ ammonium sulfate fraction was centrifuged and protein precipitate was redissolved in $0.05 \mathrm{mM}$ Tris. $\mathrm{HCl}$ buffer, $\mathrm{pH} 7.4$, dialyzed against same buffer and used for further purification. Enzyme was further purified by ion exchange chromatography with DEAE cellulose column (Dulter et al ., 1971).

\subsection{FAS Assay}

FAS assay was performed according to Li et al . (2002) with modifications. Crude protein was made up to 
a concentration of $0.5 \mathrm{mg} / \mathrm{mL}$ for the assay. Assay was carried out in 96 well plates with the final working volume of $100 \mu \mathrm{L}$. Compounds to be tested were incubated with previously made crude protein extract for 30 min at $25{ }^{\circ} \mathrm{C} .50 \mu \mathrm{L}$ of this mixture was added to $50 \mu \mathrm{L}$ of reaction mixture containing $1 \mathrm{mM}$ each of malonyl CoA and NADPH, $40 \mu \mathrm{M}$ acetyl CoA, and $2 \mathrm{mM}$ DTT in phosphate buffer $(250 \mathrm{mM})$. The microplate was read immediately for $10 \mathrm{~min}$ at $340 \mathrm{~nm}$. FAS activity was calculated by subtracting the optical density (OD) obtained at $1 \mathrm{~min}$ from the OD obtained at $10 \mathrm{~min}$. FAS activity was calculated and compared with that of control and test compounds. DMSO was taken as control as it was used to dilute the compounds. The $\mathrm{IC}_{50}$ was determined by linear regression. The negative control consisted of protein plus reaction buffer. DMSO (1\%) was also tested and it did not interfere with FAS activity. Another control consisted of buffer reaction without protein.

FAS activity was determined by the rate of oxidation of NADPH to NADP which was monitored at $340 \mathrm{~nm}$. The change in concentration of NADPH during oxidation was calculated using the following equation:

$\Delta \mathrm{C}=\Delta \mathrm{A} / \mathrm{E}$

Where, $\Delta \mathrm{C}$ was change in the concentration of NADPH, $\triangle \mathrm{A}$ was change in absorbance, and $\mathrm{E}$ was extinction coefficient of NADPH $(\mathrm{E} 340 \mathrm{~nm}=6.22 \mathrm{mM}-1[?] \mathrm{cm}-1)$. FAS activity was expressed as nM NADPH oxidized $/ \mathrm{min} / \mathrm{mg}$ protein.

\subsection{Molecular docking studies}

Molecular docking studies were carried out to explain the possible binding mode of the purified compound to FAS. Since the structure of the purified inhibitor (Phormidin) was similar to Cerulenin, the crystal structure with protein data bank (PDB) ID 4LS7 was selected as receptor which is of Bacillus subtilis FAS II betaketoacyl-ACP synthase II (FabF) domain, with non-covalently bonded Cerulenin. Similarly, for studying the interactions of the ligand with mammalian FAS I, PDB 3HHD (Pappenberger et al., 2010) consisting of human FAS-I's KS-MAT domain was taken as model. Prior to the docking studies, the receptor structure was prepared by deleting the crystallographic water molecules and adding hydrogen to polar moities. Later, the disulphide bond lengths were corrected and a minimization was performed by applying a RMSD cut off $0.30 \AA$ using a force field OPLS 2001. In the PDB structure of 4LS7 (Trajtenberg et al. , 2014), Cerulenin at the active site was taken as reference and grid was generated with $15 \times 15 \times 15 \AA$ volume surrounding the ligand. In the case of PDB structure 3HHD, according to Von Wettstein-Knowles et al. (2006), active site residues Cys161, His331 and His293 play crucial roles in FAS I's activity. Hence, these residues were taken as the centroid and grid was generated with a box of $15 \times 15 \times 15 \AA$. Docking simulation was performed using extra precision (XP) docking method implemented in Schrodinger version 9.4.0 (Friesneret al., 2006).

\subsubsection{Calculation of binding free energies}

The docked poses with highest glide score were selected and binding free energies for the protein-ligand complex were calculated using Prime MM-GBSA (Friesner et al. , 2006). Prime MM-GBSA generates energy properties for the ligand, the receptor, and complex structure along with energy differences relating to strain and binding. Prime calculates the binding free energy using the equation:

$\Delta \mathrm{G}$ (bind) $=$ E_complex (minimized) $-($ Eligand (minimized $)+$ E_receptor (minimized $))$

\subsubsection{ADME prediction}

In a drug design point of view the ADME (absorption, distribution, metabolism, and excretion) properties of the newly found compound, Phormidin, compared to the standard, Cerulenin and C75 were predicted using the Schrödinger suite's Qikprop module (QikProp, version 3.5, Schrödinger, LLC, New York,). Also, Qikprop can predict ADME of any possible drug leads by comparing the compound scaffold with known database and analyzing its similarity within a class of compounds (Schrödinger Release 2015: QikProp, Schrödinger, LLC, New York, NY, 2016.).

\section{Results}




\subsection{Silica column chromatography}

FAS inhibition activity guided purification of the extract prepared as described above was done by silica column chromatography ( $5 \times 30 \mathrm{~cm}$ column) and 240 mesh size silica as stationary phase. Column was subjected to gradient elution using ethyl acetate to methanol, and finally by dichloromethane. The compound got eluted at dichloromethane:methanol, at 1:1 and precipitated in white waxy form, when excess methanol was added to the eluant. Further purification steps were carried out as described in the methods section to yield the purified compound. Final purification was carried out with HPLC provided with Extend-C18 column of $1.8 \mu \mathrm{m}, 2.1 \times 50 \mathrm{~mm}$, Diode Array Detector in combination with Chem32, Chemstation software.

\subsection{Structure elucidation}

The Fourier transform infrared spectroscopy (FTIR) spectrum revealed the presence of alkenes, alkanes, hydroxy and aldehyde groups as shown in Supplementary Figure. Similarly, from QTOF MS/MS data, $m / z$ value of 349.093from which its molecular formula was determined to be $\mathrm{C}_{20} \mathrm{H}_{31} \mathrm{NO}_{4}$. This was in match with the molecular composition calculated by CHN analysis which gave a value of C: $0.687, \mathrm{H}: 0.089, \mathrm{~N}: 0.040, \mathrm{O}$ : 0.183. The molecular weight of the compound was later calculated to be $349.475 \mathrm{~g} / \mathrm{mol}$. The fragmentation data search from LC MS/MS spectrum did not match with any compound from the database (Figure 1). So, NMR data was required for structure solution. Hence different NMR spectra were made (Figure 2a and b.). The structure of the novel compound was resolved from the LC MS/MS data together with NMR spectra. From the ${ }^{1} \mathrm{HNMR}$ and ${ }^{13} \mathrm{C}$ NMR spectra, the isolated compound was confirmed as (3S,5Z,7S,8Z)-7-amino3,5-dihydroxy-2-methyl-13-[(1s,4s)-4-hydroxycyclohexa-2,5-dien-1-yl]trideca-5,8-dien-4-one (Figures 4 and 5 respectively). The ${ }^{1} \mathrm{H}$ and ${ }^{13} \mathrm{C}$ NMR spectra pointed to a compound with long aliphatic chain and an open ring. Signals at $\delta \mathrm{H} 7.26$ correlated with $\delta \mathrm{C} 67.62$ suggested the presence of an $\mathrm{NH}$ group. $\delta \mathrm{H}$ at 2.46 to 2.62 and $\delta \mathrm{C}$ at 29.64 pointed to the presence of $\mathrm{CH}_{2}$ groups. $\delta \mathrm{H}$ at 1.25 to 1.67 indicated $\mathrm{CH}_{3}$ and 5.23 to 5.27 of $\mathrm{C}=\mathrm{CH}_{2}$. This in correlation with $\delta \mathrm{C} 19.76$ confirmed the long aliphatic chain. $\delta \mathrm{C}$ at 169.17 indicated a $\mathrm{CH}=\mathrm{CH}$ and an the absence of any signal corresponding to aromatic ring inferred towards an open ring structure and named as Phormidin (Figure 3). Mass difference between fragments in MS/MS and from FTIR spectra confirmed the presence of the said groups. Structural search of the available literature revealed no reported compound and the purified compound was concluded to be entirely a novel one.

\subsection{Cytotoxic effect of Phormidin}

Cytotoxicity test revealed that Phormidin has a median cell line lethal dose $\left(\mathrm{LD}_{50}\right)$ of $89.65(\mu \mathrm{g} / \mathrm{mL})$ against L929 cell lines. Viability percentage was calculated using the formula,

$\%$ viability $=(\mathrm{OD}$ of Test/OD of Control $) \times 100$, where control OD was 0.993

$\%$ viability at various concentrations of the new FAS inhibitor, Phormidin is depicted in the Table 1.

In-vitro cytotoxicity of Phormidin, and Cerulenin and C75 on cultured A549 cells are calculated on the formula as in the previous case and depicted in Table 1 as well.

In-vitro cytotoxic effect of Phormidin on cultured A549 cells is calculated on the formula shown above and the values are given in Table 1 . The $\mathrm{LD}_{50}$ value calculated from the above are also shown in the Table 1.

\subsection{FAS assay using partially purified FAS I and II}

The Assays using partially purified enzymes were performed to verify the FAS I and FAS II inhibitory activities of Phormidin (Figure 4a. and b.). Phormidin showed comparable results with Cerulenin and C75 at lower concentration of the title compound and higher inhibition at higher concentration of Phormidin. The graphs (Figures 5a. and b.) were plotted with change in concentration of NADP to NADPH against time. Each point in graph was the concentration of NADPH measured at $340 \mathrm{~nm}$ (Table 2).

\subsection{Docking studies}

Docking studies were carried out to understand the possible binding sites and thus the mechanism of action of Phormidin against bacterial FAS II and human FAS I. Crystal structure of Bacillus subtilisFAS II with 
inhibitor Cerulenin bonded at beta-ketoacyl-ACP synthase II domain and human FAS IKS-MAT di-domain were considered as a model for the studies. Binding results were interpreted based on the scores obtained in docking studies, as well as the theoretical binding energies calculated from the docked poses. Possible amino acid residues involved in binding and the type of interactions made by Phormidin with active site residues are shown in Figure 4a. for FAS II and in Figure 4b. in the case of FAS I. As seen from the Table 3, for both FAS II and FAS I, the glide scores as well as the theoretically calculated binding energies are better for Phormidin compared to that of both the other inhibitors, Cerulenin and C75. Glide score is calculated based on different parameters of ligand-protein interactions and it represents the overall affinity of ligandprotein binding. MMGBSA simulates binding free energy of ligand-protein interaction; more negative values represent tighter binders. Parameters like number of H-bonds between ligand atoms and active site residues, ligand interaction with number of hydrophobic residues and the total number of van der Waals contacts involved in ligand binding indicates the affinity and strength of ligand enzyme interactions. Table 4 gives a comparison of total number of these parameters with respect to Phormidin and other two FAS inhibitors in FAS II and FAS I. It can be clearly seen that Phormidin has stronger interaction with both FAS II and FAS I enzymes when compared to the other known inhibitors. Also, the results of ADME prediction have been summarized in Table 5.

\section{DISCUSSION}

A novel compound named, Phormidin was isolated from the marine cyanobacteriumPhormidium ambiguum

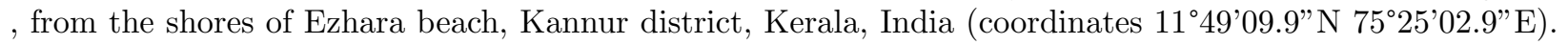
Structure of the compound was elucidated by a combination of UV, FTIR, NMR and LC MS/MS methods. The isolated compound was found to have a molecular weight of 349.475 Daltons and has a structure similar to C75 and Cerulenin, known fatty acid synthase inhibitor drugs. Phormidin has a 20 carbon skeleton composed of a long aliphatic chain with an amide group attached to $13^{\text {th }}$ carbon and a 6 carbon open ring at one end. The two non polar methyl groups at one end make Phormidin lipophilic in nature. The compound is readily soluble in chloroform and DMSO.

How good a lead molecule can act as a drug candidate is termed 'drug likeness', a measure of the compound's bioavailability and potency which is calculated based on properties like solubility in aqueous and organic phases, molecular weight etc. Lipinski's rule of five is a set of four rules that can be correlated to check how much the compound is 'druglike' (Lipinski et al ., 2001). Phormidin fits to all the four of the 'Lipinski's rule of five' which also predicts whether a compound is orally active or not. The Lipinski's rule wants the number of hydrogen bond donors to be less than 5 and number of hydrogen bond acceptors to be less than 10 . The number of hydrogen bond acceptors is 5 and donors are 4 for Phormidin, extending towards the bacterial FAS II. Likewise, the molecular weight of Phormidin is 349.4 Daltons and it is within the molecular weight limit of 500 Dalton for any compound to be an oral drug. And, finally the $\log _{\mathrm{p}}$ value which is the ratio of solubility of a compound in aqueous phase to that of an organic phase and has a maximum value of 5 , for Phormidin it was found to be 2.75. Since it obeys all 4 of Lipinski's rules, Phormidin can be considered as a good drug lead molecule. Along with Lipinski's rule of five there are some more discussed criteria which are now used to establish the 'druglikeness' of any compound like molar refractivity, total number of atoms present and the total topological surface area of a compound etc. The molar refractivity of Phormidin comes to around 104.76 which indicate the polarizability of the compound. The total number of atoms in the title compound is 25 and for a good drug lead the total number of atoms must be from 20 to 70 , including H-bond donors. Similarly, the maximum topological surface area (TPSA) of a good drug lead is considered to be around $140 \AA^{2}$, exceeding which usually results in poor cell membrane permeation. Phormidin is having a TPSA value of $103.78 \AA^{2}$ indicating a moderate cell membrane penetrating capacity. All the above discussed properties and specifications of Phormidin place it better than the known FAS inhibitors, Cerulenin and C75.

Enzyme inhibition assay with both bovine FAS I and bacterial FAS II showed that Phormidin is a better inhibitor compared to the standard FAS inhibitor Cerulenin. Also Phormidin showed better inhibition against bacterial FAS II compared to bovine FAS-I. This could be either due to the difference in activity towards 
FAS I and FAS II or might be related to the extent of purity of the enzymes used in the assay. The bovine enzyme extract used for the assay was partially purified which may consist of both cytoplasmic FAS I and mitochondrial FAS II enzymes. This aspect has to be clarified further by assaying with pure FAS I and FAS II enzymes.

The new compound did not show marked cytotoxicity (IC50>30 $\mu \mathrm{g} / \mathrm{mL}$ ) on the tested normal cell lines, and was simultaneously FAS I and FAS II inhibitors. Likewise, effect of Phormidin on cultured human alveolar basal epithelial cells; A549 cells showed an $\mathrm{IC}_{\mathbf{5 0}}$ value $76.034 \mu \mathrm{g} / \mathrm{mL}$, compared to $86.419 \mu \mathrm{g} / \mathrm{mL}$ for Cerulenin and $99.034 \mu \mathrm{g} / \mathrm{mL}$ for C75. This shows that Phormidin acts on normal cell line in a limited way only, but is more active against cancer cell lines. This could be because Phormidin acts on FAS expression and its activity is limited (Deepa et al ., 2013). Since there is added free fatty acids present in cultured media, inhibition of FAS may limit the cell growth but would not affect much on its growth rate. But in cancer cell line, since there is an increased need for fatty acids beyond what is available in culture media due to increased expression of FAS, inhibiting FAS will prevent the formation of new fatty acids and thus may directly affect the growth rate of cancer cell. Interestingly, FAS assay using crude Bacillus subtilis FAS II and bovine FAS I showed similar pattern of activity with Phormidin where it showed higher activity than Cerulenin and C75. This was well in accordance with the docking simulation results obtained comparing the three different inhibitors against FAS. As seen from the Figures 6a. and b. and Tables $4,5 \& 8$. For both FAS II and FAS I docking glide scores as well as binding energies are in the order Phormidin $<$ Cerulenin $<\mathrm{C} 75$ demonstrating that Phormidin would be better than Cerulenin and C75.

In designing good FAS inhibitor, as a lead compound Phormidin stands out as a promising candidate. The two other inhibitors, both Cerunenin and C75 are used as FAS inhibitors in different scenarios but have limitations. Cerulenin contains the reactive epoxy group that may interact with other proteins and may act on other off targets other than FAS like interfering with palmitoylation (a posttranslational modification, there by fatty acids are attached to amino acids allowing key signaling proteins to attach to the plasma membrane), cholesterol synthesis and proteolysis (Lupu and Menendez, 2006). Also, this epoxy group contributes to lower stability of Cerulenin. C75 was designed to avoid this epoxy group to increase stability and availability, but this redesign reduced potency of C75 (Kuhajda et al ., 2000). Phormidin does not contain this epoxy group and thus might have less side effects compared to Cerulenin and C75 due to non binding to off targets and also improved stability.

Results of docking studies carried out to investigate the mode of interaction of Phormidin with FAS I and FAS II was in accordance with the assay data (Figures 9 and 10). In docking simulations with FAS I and FAS-II, Phormidin showed better score compared to Cerulenin and C75. Even though the active site residues are different for both FAS IKS MAT domain and FAS II FasF domain interaction of Phormidin showed remarkably similar results.

From the enzyme assay and docking studies it is clear that Phormidin is more active than Cerulenin, even without the reactive epoxy group and hence, it must be also stable than Cerulenin. It is also better active than C75 as found in this study but Phormidin's interaction with CPT has to be investigated and can be further re-engineered as a good lead molecule for suitable uses.

\section{Acknowledgements}

The authors acknowledge National Institute for Interdisciplinary Science and Technology, Thiruvananthapuram, for NMR spectra and the School of environment studies, Mahatma Gandhi University, Kottayam, for LC-MS MS data.

\section{Conflict of Interest}

None.

Funding 
Funding was provided by the Ministry of Earth science, Government of India at the Department of Biotechnology and Microbiology, Kannur University.

\section{References}

AHMAD, P.M., STIRLING, L.A., AHMAD, F., 1981. Partial Characterization of Fatty Acid Synthase of Propionibacterium shermanii. Microbiology 127, 121-129. https://doi.org/10.1099/00221287-127-1-121

Arung, E.T., Wicaksono, B.D., Handoko, Y.A., Kusuma, I.W., Yulia, D., Sandra, F., 2009. Anti-Cancer Properties of Diethylether Extract of Wood from Sukun (Artocarpus altilis) in Human Breast Cancer (T47D) Cells. Tropical Journal of Pharmaceutical Research 8. https://doi.org/10.4314/tjpr.v8i4.45223

Bhatt, A., Molle, V., Besra, G.S., Jacobs, W.R., Kremer, L., 2007. The Mycobacterium tuberculosis FAS-II condensing enzymes: their role in mycolic acid biosynthesis, acid-fastness, pathogenesis and in future drug development. Mol. Microbiol. 64, 1442-1454. https://doi.org/10.1111/j.1365-2958.2007.05761.x

Brusselmans, K., De Schrijver, E., Heyns, W., Verhoeven, G., Swinnen, J.V., 2003. Epigallocatechin-3gallate is a potent natural inhibitor of fatty acid synthase in intact cells and selectively induces apoptosis in prostate cancer cells. Int. J. Cancer 106, 856-862. https://doi.org/10.1002/ijc.11317

Chalbos, D., Chambon, M., Ailhaud, G., Rochefort, H., 1987. Fatty acid synthetase and its mRNA are induced by progestins in breast cancer cells. J. Biol. Chem. 262, 9923-9926.

Deepa, P.R., Vandhana, S., Krishnakumar, S., 2013. Fatty acid synthase inhibition induces differential expression of genes involved in apoptosis and cell proliferation in ocular cancer cells. Nutr Cancer 65, 311-316. https://doi.org/10.1080/01635581.2013.748923

Dixit, R.B., Suseela, M.R., 2013. Cyanobacteria: potential candidates for drug discovery. Antonie Van Leeuwenhoek 103, 947-961. https://doi.org/10.1007/s10482-013-9898-0

Dutler, H., Kull, A., Mislin, R., 1971. Fatty acid synthetase from pig liver. 2. Characterization of the enzyme complex with oxidoreductase activity for alicyclic ketones as a fatty acid synthetase. Eur. J. Biochem. 22, 213-217.

Filimonov, D.A., Akimov, D.V., Poroikov, V.V., 2004. The Method of Self-Consistent Regression for the Quantitative Analysis of Relationships Between Structure and Properties of Chemicals. Pharmaceutical Chemistry Journal 38, 21-24. https://doi.org/10.1023/B:PHAC.0000027639.17115.5d

Friesner, R.A., Murphy, R.B., Repasky, M.P., Frye, L.L., Greenwood, J.R., Halgren, T.A., Sanschagrin, P.C., Mainz, D.T., 2006. Extra precision glide: docking and scoring incorporating a model of hydrophobic enclosure for protein-ligand complexes. J. Med. Chem. 49, 6177-6196. https://doi.org/10.1021/jm051256o

Gago, G., Diacovich, L., Arabolaza, A., Tsai, S.-C., Gramajo, H., 2011. Fatty acid biosynthesis in actinomycetes. FEMS Microbiol. Rev. 35, 475-497. https://doi.org/10.1111/j.1574-6976.2010.00259.x

Kridel, S.J., Axelrod, F., Rozenkrantz, N., Smith, J.W., 2004. Orlistat is a novel inhibitor of fatty acid synthase with antitumor activity. Cancer Res. 64, 2070-2075.

Kuhajda, F.P., Jenner, K., Wood, F.D., Hennigar, R.A., Jacobs, L.B., Dick, J.D., Pasternack, G.R., 1994. Fatty acid synthesis: a potential selective target for antineoplastic therapy. Proc. Natl. Acad. Sci. U.S.A. 91, 6379-6383.

Kuhajda, F.P., Pizer, E.S., Li, J.N., Mani, N.S., Frehywot, G.L., Townsend, C.A., 2000. Synthesis and antitumor activity of an inhibitor of fatty acid synthase. Proc. Natl. Acad. Sci. U.S.A. 97, 3450-3454. https://doi.org/10.1073/pnas.050582897

Li, X.-C., Joshi, A.S., ElSohly, H.N., Khan, S.I., Jacob, M.R., Zhang, Z., Khan, I.A., Ferreira, D., Walker, L.A., Broedel, S.E., Raulli, R.E., Cihlar, R.L., 2002. Fatty acid synthase inhibitors from plants: isolation, structure elucidation, and SAR studies. J. Nat. Prod. 65, 1909-1914. https://doi.org/10.1021/np020289t 
Lipinski, C.A., Lombardo, F., Dominy, B.W., Feeney, P.J., 2001. Experimental and computational approaches to estimate solubility and permeability in drug discovery and development settings. Adv. Drug Deliv. Rev. 46, 3-26.

Liu, B., Wang, Y., Fillgrove, K.L., Anderson, V.E., 2002. Triclosan inhibits enoyl-reductase of type I fatty acid synthase in vitro and is cytotoxic to MCF-7 and SKBr-3 breast cancer cells. Cancer Chemother. Pharmacol. 49, 187-193. https://doi.org/10.1007/s00280-001-0399-x

Liu, H., Liu, J.-Y., Wu, X., Zhang, J.-T., 2010. Biochemistry, molecular biology, and pharmacology of fatty acid synthase, an emerging therapeutic target and diagnosis/prognosis marker. Int J Biochem Mol Biol 1, 69-89.

Loftus, T.M., Jaworsky, D.E., Frehywot, G.L., Townsend, C.A., Ronnett, G.V., Lane, M.D., Kuhajda, F.P., 2000. Reduced food intake and body weight in mice treated with fatty acid synthase inhibitors. Science 288, 2379-2381.

Lupu, R., Menendez, J.A., 2006. Pharmacological inhibitors of Fatty Acid Synthase (FASN)-catalyzed endogenous fatty acid biogenesis: a new family of anti-cancer agents? Curr Pharm Biotechnol 7, 483-493.

Maier, T., Leibundgut, M., Boehringer, D., Ban, N., 2010. Structure and function of eukaryotic fatty acid synthases. Q. Rev. Biophys. 43, 373-422. https://doi.org/10.1017/S0033583510000156

Migita, T., Ruiz, S., Fornari, A., Fiorentino, M., Priolo, C., Zadra, G., Inazuka, F., Grisanzio, C., Palescandolo, E., Shin, E., Fiore, C., Xie, W., Kung, A.L., Febbo, P.G., Subramanian, A., Mucci, L., Ma, J., Signoretti, S., Stampfer, M., Hahn, W.C., Finn, S., Loda, M., 2009. Fatty acid synthase: a metabolic enzyme and candidate oncogene in prostate cancer. J. Natl. Cancer Inst. 101, 519-532. https://doi.org/10.1093/jnci/djp030

Moche, M., Schneider, G., Edwards, P., Dehesh, K., Lindqvist, Y., 1999. Structure of the complex between the antibiotic cerulenin and its target, beta-ketoacyl-acyl carrier protein synthase. J. Biol. Chem. 274, 6031-6034.

Ohno, T., Awaya, J., Kesado, T., Nomura, S., Ōmura, S., 1974. Mechanism of Action of CM-55, a Synthetic Analogue of the Antilipogenic Antibiotic Cerulenin. Antimicrob Agents Chemother 6, 387-392.

Pappenberger, G., Benz, J., Gsell, B., Hennig, M., Ruf, A., Stihle, M., Thoma, R., Rudolph, M.G., 2010. Structure of the human fatty acid synthase KS-MAT didomain as a framework for inhibitor design. J. Mol. Biol. 397, 508-519. https://doi.org/10.1016/j.jmb.2010.01.066

Rendina, A.R., Cheng, D., 2005. Characterization of the inactivation of rat fatty acid synthase by C75: inhibition of partial reactions and protection by substrates. Biochem. J. 388, 895-903. https://doi.org/10.1042/BJ20041963

Trajtenberg, F., Altabe, S., Larrieux, N., Ficarra, F., de Mendoza, D., Buschiazzo, A., Schujman, G.E., 2014. Structural insights into bacterial resistance to cerulenin. FEBS J. 281, 2324-2338. https://doi.org/10.1111/febs.12785

Vazquez-Martin, A., Colomer, R., Brunet, J., Lupu, R., Menendez, J.A., 2008. Overexpression of fatty acid synthase gene activates HER1/HER2 tyrosine kinase receptors in human breast epithelial cells. Cell Prolif. 41, 59-85. https://doi.org/10.1111/j.1365-2184.2007.00498.x

von Wettstein-Knowles, P., Olsen, J.G., McGuire, K.A., Henriksen, A., 2006. Fatty acid synthesis. Role of active site histidines and lysine in Cys-His-His-type beta-ketoacyl-acyl carrier protein synthases. FEBS J. 273, 695-710. https://doi.org/10.1111/j.1742-4658.2005.05101.x

Wakil, S.J., 1989. Fatty acid synthase, a proficient multifunctional enzyme. Biochemistry 28, 4523-4530. https://doi.org/10.1021/bi00437a001

Wang, Y.Y., Kuhajda, F.P., Li, J., Finch, T.T., Cheng, P., Koh, C., Li, T., Sokoll, L.J., Chan, D.W., 2004. Fatty acid synthase as a tumor marker: its extracellular expression in human breast cancer. J. Exp. Ther. Oncol. 4, 101-110. 
White, S.W., Zheng, J., Zhang, Y.-M., Rock, null, 2005. The structural biology of type II fatty acid biosynthesis. Annu. Rev. Biochem. 74, 791-831. https://doi.org/10.1146/annurev.biochem.74.082803.133524

Wijffels, R.H., Kruse, O., Hellingwerf, K.J., 2013. Potential of industrial biotechnology with cyanobacteria and eukaryotic microalgae. Curr. Opin. Biotechnol. 24, 405-413. https://doi.org/10.1016/j.copbio.2013.04.004

Zhou, W., Simpson, P.J., McFadden, J.M., Townsend, C.A., Medghalchi, S.M., Vadlamudi, A., Pinn, M.L., Ronnett, G.V., Kuhajda, F.P., 2003. Fatty acid synthase inhibition triggers apoptosis during S phase in human cancer cells. Cancer Res. 63, 7330-7337.

\section{FIGURE CAPTIONS}

Figure 1: LCMS/MS Spectrum of Phormidin

Figure 2: ${ }^{\mathrm{H}} \mathrm{NMR}(\mathrm{a})$ and ${ }^{\mathrm{C}} \mathrm{NMR}(\mathrm{b})$ spectrum of Phormidin

Figure 3: Structure of (3S,5Z,7S,8Z)-7-amino-3,5-dihydroxy-2-methyl-13-[(1s,4s)-4-hydroxycyclohexa-2,5dien-1-yl] trideca-5,8-dien-4-one, Phormidin

Figure 4: FAS inhibition assay with bacterial FAS II (a) and bovine FAS I enzyme (b)

Figure 5: Phormidin at active site $B a \varsigma \imath \lambda \nu_{\varsigma} \sigma v \beta \tau \imath \lambda \iota \varsigma \beta$-ketoacyl-ACP synthase II (FAS II) (a) and human FAS IKS-MAT domain (FAS I) (b).

\section{SUPPLEMENTARY FIGURE CAPTION}

Supplementary Figure: FTIR Spectrum of Phormidin taken as neat

\section{TABLES}

Table 1: In-vitro anti-proliferative effect of Phormidin, C75 and Cerulenin on cultured L929 and A549 cells

$-54.679$

Phormidin

Table 2: Percentage inhibition of Phormidin on FAS I and FAS II, compared to Cerulenin and C75 taken as standard inhibitors

\begin{tabular}{lll}
\hline FAS-I assay compared with known inhibitors & FAS-I assay compared with known inhibitors & FAS-I assay compared wit \\
\hline & Control & Cerulenin \\
Average $\Delta \mathrm{C}$ & 0.051383 & 0.032476 \\
Inhibition compared to control & Inhibition compared to control & $36.49 \%$ \\
& & Cerulenin \\
& Control & FAS-II assay compared wi \\
FAS-II assay compared with known inhibitors & FAS-II assay compared with known inhibitors & 0.03955 \\
Average $\Delta \mathrm{C}$ & 0.05037 & $21.48 \%$ \\
Inhibition compared to control & Inhibition compared to control & \\
& & \\
\hline
\end{tabular}

Table 3: Compared docking result of Phormidin, Cerulenin and C75 against Bacillus

FAS II / FAS I 
Phormidin

\begin{tabular}{llll}
\hline Compound & Number of Hydrogen bonds & Number of Hydrogen bonds & Number of Hydrophobicresidues \\
\hline & FAS II & FAS I & FAS II \\
Phormidin & 4 & 3 & 9 \\
Cerulenin & 3 & 2 & 8 \\
C 75 & 1 & 3 & 8 \\
\hline
\end{tabular}

Table 5: ADME predictions of Phormidin compared to Cerulenin and C75 predicted using QikProp module of Schrodinger suit.

\begin{tabular}{lllllll}
\hline Compoud ID & \#stars $^{\mathbf{a}}$ & \#rotor $^{\mathbf{b}}$ & SASA $^{(\AA)}$ & Donor HB $^{\mathbf{d}}$ & Accept HB $^{\text {e }}$ & QPlogPo/w $^{\mathbf{f}}$ \\
\hline Phormidin Cerulenin C75 & 000 & 1079 & 726.16223 .27254 .32 & 511 & 755 & 1.8820 .6972 .6 \\
\hline
\end{tabular}

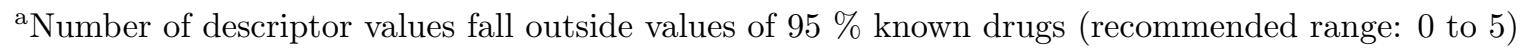

${ }^{b}$ Number of rotatable bonds (recommended range: 0-15)

c Total solvent accessible surface area (SASA) in square angstroms (recommended range: 300 to 1000)

${ }^{\mathrm{d}}$ Number of hydrogen-bond donors (recommended range: 0 to 6 )

e Number of hydrogen-bond acceptors (recommended range: 2 to 20 )

${ }^{\mathrm{f}}$ Predicted octanol/water partition coefficient (recommended range: -2 to 6.5 )

${ }^{\mathrm{g}}$ Predicted skin permeability (recommended range: -8.0 to -1.0 ) 


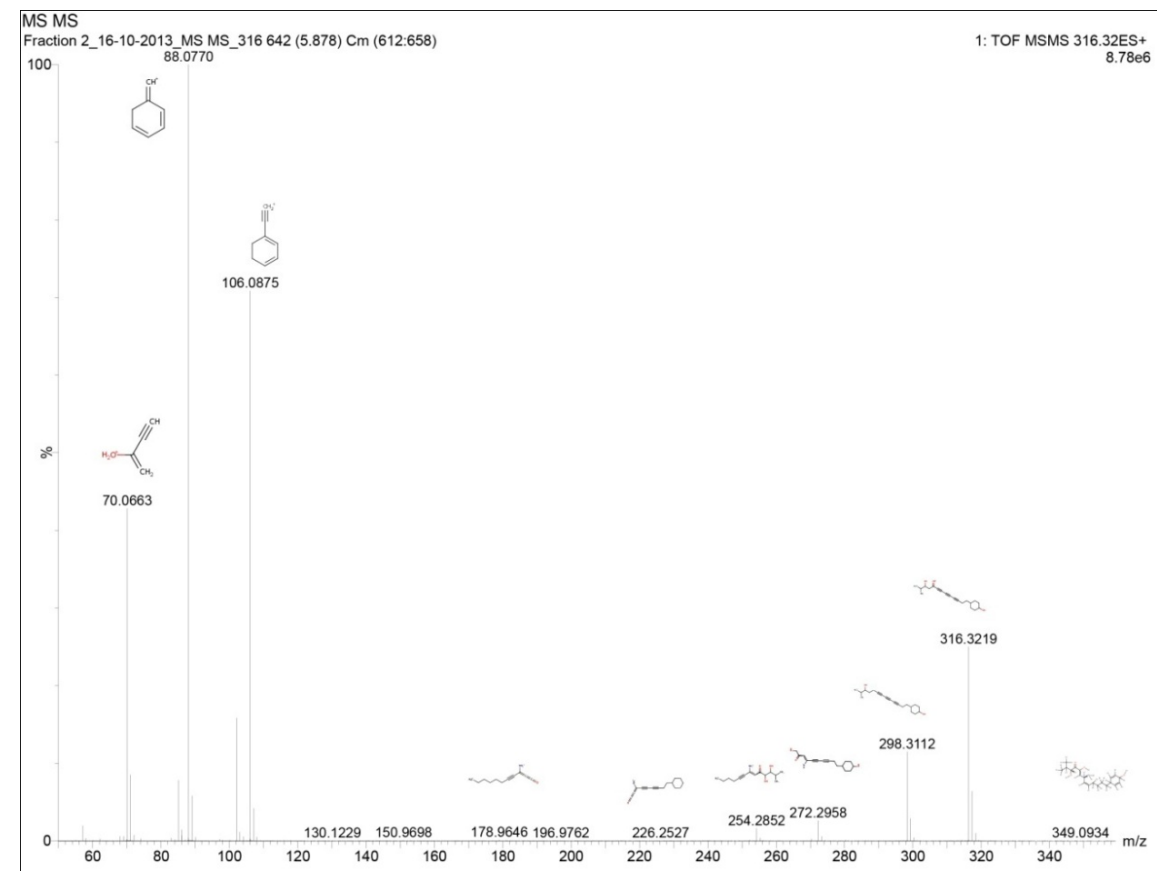

Figure 1: LCMS/MS Spectrum of Phormidin 

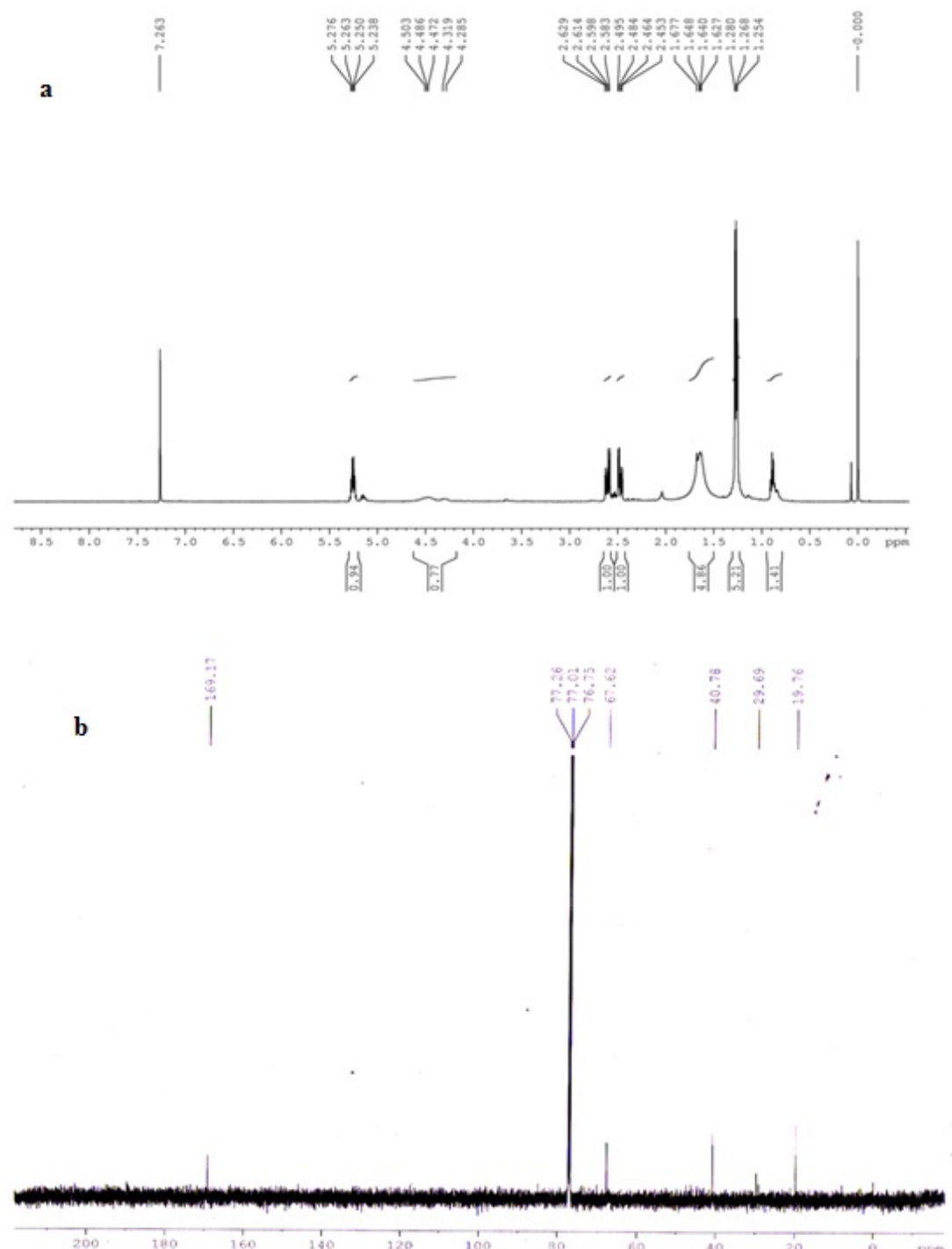

Figure 2: ${ }^{\mathrm{H}} \mathrm{NMR}$ (a) and ${ }^{\mathrm{C}} \mathrm{NMR}$ (b) spectrum of Phormidin 


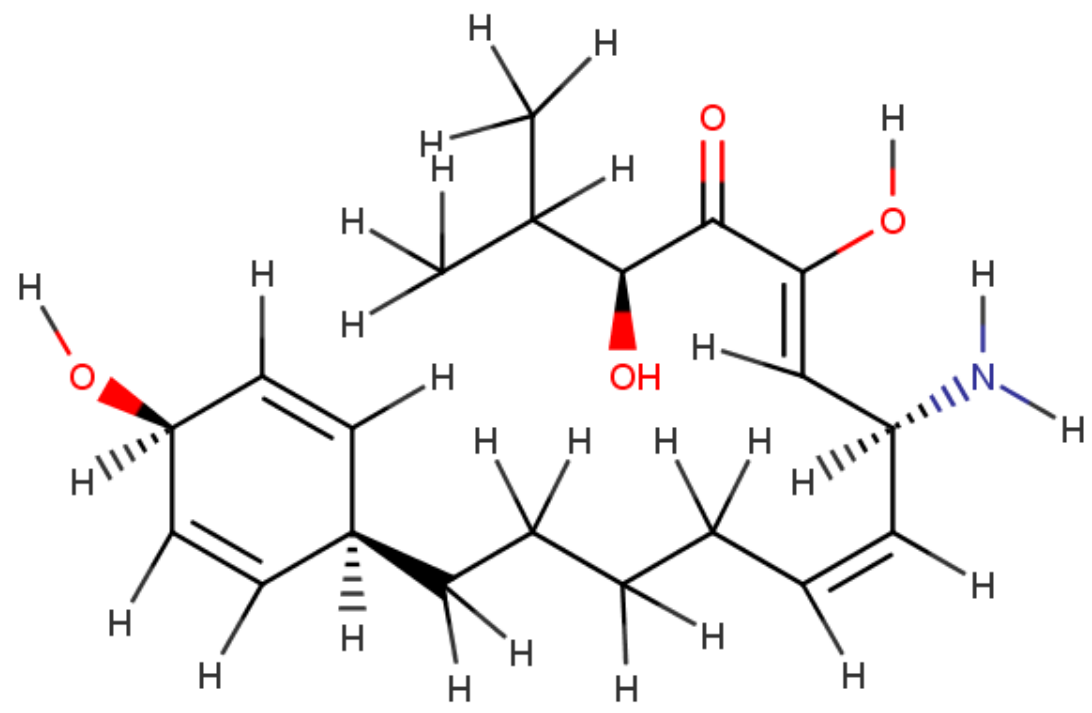

Figure 3: Structure of (3S,5Z,7S,8Z)-7-amino-3,5-dihydroxy-2-methyl-13-[(1s,4s)-4-hydroxycyclohexa-2,5dien-1-yl]trideca-5,8-dien-4-one, Phormidin
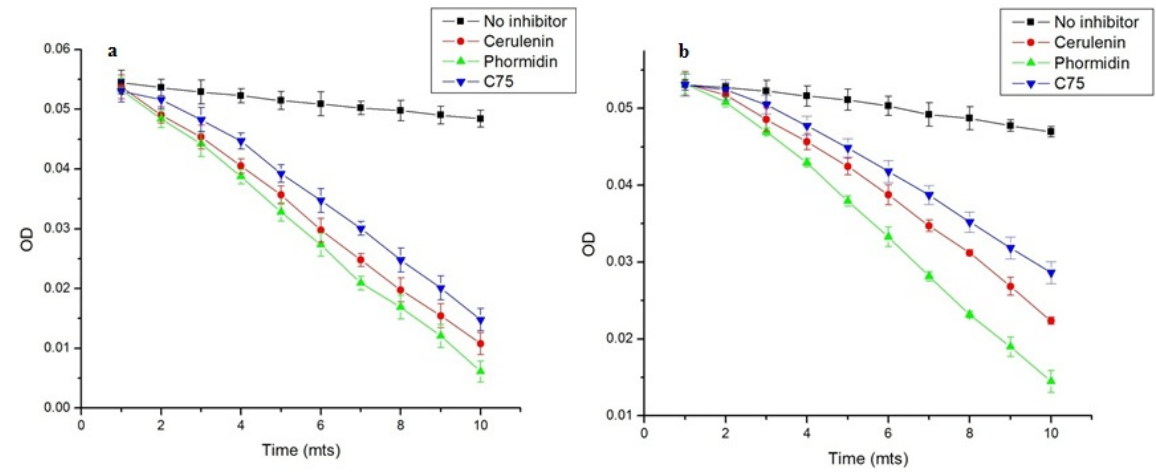

Figure 4: FAS inhibition assay with bacterial FAS II (a) and bovine FAS I enzyme (b) 


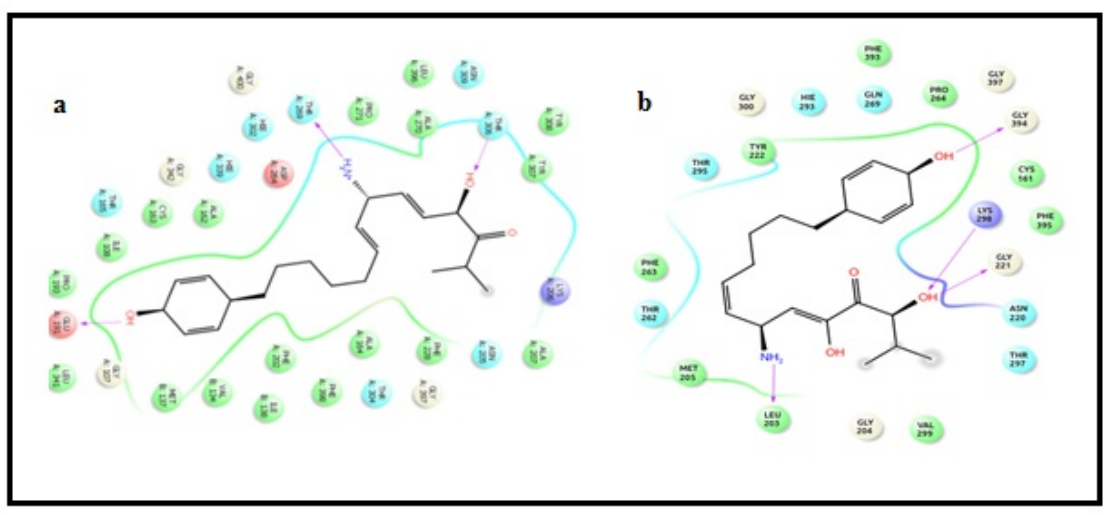

Figure 5: Phormidin at active site $B a \varsigma \imath \lambda \lambda v_{\varsigma} \sigma v \beta \tau \imath \lambda \iota \varsigma \beta$-ketoacyl-ACP synthase II (FAS II) (a) and human FAS IKS-MAT domain (FAS I) (b).

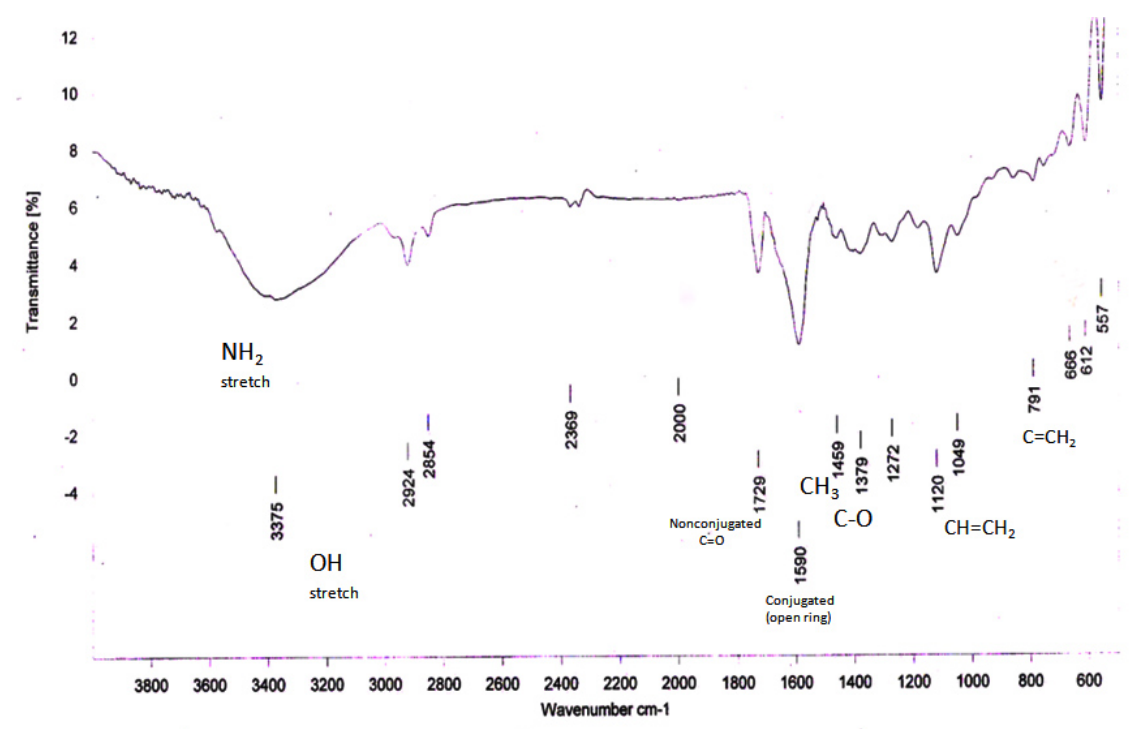

Supplementary Figure: FTIR Spectrum of Phormidin taken as neat

Bullet point summary:

What is already known :

- Cerulenin and C75 are Fatty Acid Synthase inhibitor drugs.

- Despite their in vitro efficacy, cerulenin and C75 have side effects limiting their use.

What this study adds:

- A novel compound, phormidin has been found to be Fatty Acid Synthase inhibitor.

- Phormidin showed better cytotoxicity with A549 cell line than cerulenin and C75.

\section{Clinical significance :}

- Phormidin is stabler than Cerulenin, more active than C75 and predicted less toxic.

- Phormidin can be further re-engineered as a good lead molecule for suitable uses. 